\title{
¿Acción social católica o intervención social estatal? \\ El rol del Estado en la resolución de la Cuestión Social según la Iglesia Católica chilena a inicios del siglo XX
}

\author{
Karin Sánchez Manríquez ${ }^{1}$ \\ Recibido: 15 de septiembre de 2017 - Aceptado: 20 de octubre de 2017
}

\begin{abstract}
Resumen
El objetivo de este artículo es analizar el desarrollo del pensamiento católico chileno sobre el rol del Estado para enfrentar la Cuestión Social a principios del siglo XX. Se argumenta que la Iglesia Católica chilena le daba al Estado un rol secundario en la solución de la Cuestión Social. Pese a reconocer la necesidad de establecer normativas legales para solucionar los problemas entre patrones y obreros, la realización de obras en favor de los trabajadores correspondía a iniciativas privadas que el Estado debía fomentar, lo que la Iglesia denominaba "Acción Social Católica". Esta preferencia por un Estado con una acción social limitada mostraba a una Iglesia que seguía considerándose como la institución rectora de la sociedad en tanto su accionar incluía tanto la vida terrena como también la vida después de la muerte. El Estado, al centrarse sólo en problemas terrenales, era una institución de rango menor, cobijada por la Iglesia. Se estudiarán textos escritos por sacerdotes de la jerarquía eclesiástica chilena sobre el rol del Estado en la resolución de los problemas sociales y sobre la discusión en la esfera pública de dos leyes sociales: la ley de habitación obrera de 1906 y la ley de descanso dominical de 1907.
\end{abstract}

Palabras clave: Iglesia, Estado, Cuestión Social, Legislación Social.

1 Chilena. Doctora en Historia, University of Texas at Austin, Estados Unidos. Académica, Universidad Nacional Andrés Bello. Este artículo es resultado de una investigación mayor en el marco de la tesis doctoral, financiada por Fulbright-Conicyt, titulada "Material help, moral concerns. The Chilean Ecclesiastical Hierarchy and the Social Question, 1891-1931". E-mail: ksmksm@gmail.com 


\title{
Catholic social action or State social intervention? The role of the State in the resolution of the Social Problem according to the Chilean Catholic Church at the beginning of the 20th Century
}

\begin{abstract}
The objective of this article is to analyze the development of Chilean Catholic thinking about the role of the State in facing the Social Problem at the beginning of the 20th Century. It is argued that the Chilean Catholic Church gave the State a secondary role in the solution of the Social Problem. Despite recognizing the need of establishing legal regulations to solve problems between employers and workers, the performance of works in favor of workers corresponded to private initiatives that the State should promote, what the Church called "Catholic Social Action". This preference for a State with limited social action showed a Church that continued to be considered as the governing institution of society, as its actions included both earthly life and life after death. The State, by focusing only on earthly problems, was an institution of lower rank, sheltered by the Church. The research studied some texts written by priests of the Chilean ecclesiastical hierarchy dealing with the role of the State in the resolution of social problems and the public discussion about two social laws: the 1906 Working Class Law and the 1907 Sunday Rest Law.
\end{abstract}

Keywords: Church, State, Social Problem, Social Law.

\section{Ação social católica ou intervenção social do Estado? 0 papel do Estado na resolução da Questão Social segundo a Igreja Católica Chilena no início do século XX}

\section{Resumo}

0 objetivo deste artigo é analisar o desenvolvimento do pensamento católico chileno sobre o papel do Estado para enfrentar a Questão Social a princípios do século XX. Argumenta-se que a Igreja Católica chilena tinha dado ao Estado um papel secundário na solução da Questão Social. Apesar de reconhecer a necessidade de estabelecer normativas legais para resolver problemas entre empregadores e trabalhadores, a realização de obras a favor dos trabalhadores correspondia a iniciativas privadas que o Estado devia promover, o que a Igreja denominou "Ação Social Católica". Essa preferência por um Estado com uma ação social limitada mostrava uma Igreja que seguia considerando-se como a instituição governante da sociedade, tanto na sua ação incluía a vida terrena como também a vida após a morte. 0 Estado, ao centrar-se só em problemas terrenais, era uma instituição de alcance inferior, protegida pela Igreja. Vão ser estudados os textos escritos por sacerdotes da hierarquia eclesiástica chilena sobre o papel do Estado na resolução de problemas sociais e na discussão na esfera pública de duas leis sociais: a lei da habitação trabalhadora de 1906 e a lei do descanso dominical de 1907.

Palavras-chave: Igreja, Estado, Questão Social, Legislação Social. 


\section{Introducción}

La Cuestión Social, definida como el conjunto de problemas que las clases populares de los países del mundo occidental experimentaron como resultado de la industrialización a fines del siglo XIX, provocó, entre otros efectos, un cambio en la concepción del rol que el Estado debía tener para dirimir los conflictos entre patrones y obreros. Comenzaron a darse legislaciones sociales que inauguraron la actuación estatal en un ámbito no considerado antes como relevante en el espacio público: lo social. Las propuestas de soluciones vinieron desde todas las corrientes políticas (Cruzat \& Tironi, 1987). Con pavor, las elites latinoamericanas veían cómo los nuevos grupos socialistas ofrecían soluciones radicales que no sólo le daban más poder al Estado, sino que un rol reducido a las oligarquías hasta entonces dominantes (Romero, 2007: 218-223). Estas últimas, las más de las veces, sectores conservadores identificados con el catolicismo, proponían respuestas caritativas para ayudar a los nuevos pobres, acción social que no incluía una activa y/o protagónica acción del Estado. La autoridad política tenía una actitud secundaria, de garante del orden social, debiendo intervenir sólo cuando las instancias civiles habían fracasado.

La Iglesia católica, en este contexto, fue un actor relevante. Como una institución que propugnaba el amor al prójimo, estaba en la necesidad de dar una respuesta a los reclamos de la clase obrera, pero sin modificar el statu quo -una sociedad jerárquicamente organizada- en el cual el catolicismo sostenía su autoridad. El objetivo de este artículo es analizar el desarrollo del pensamiento católico chileno sobre el rol del Estado para enfrentar la Cuestión Social a principios del siglo XX. ¿Bajo qué premisas la Iglesia entendía la intervención social del Estado? ¿Asumía la Iglesia que el Estado era el encargado de llevar a cabo actividades en favor del obrero o prefería que su rol se limitara a crear normativas legales para que la sociedad civil actuara? Postulamos en este artículo que, en las dos primeras décadas del siglo XX, la postura de la Iglesia chilena le daba al Estado un rol secundario en la solución de la Cuestión Social. Si bien se reconocía la necesidad de establecer normativas legales para solucionar los problemas entre patrones y obreros, la realización de obras en favor de los trabajadores debía estar a cargo de iniciativas privadas que el Estado debía fomentar, lo que la Iglesia denominaba "Acción Social Católica". Esta postura de la Iglesia mostraba que, pese a la crítica católica hacia los excesos del liberalismo por provocar el sufrimiento de las clases trabajadoras, el apoyo de la Iglesia al impulso particular coincidía con los principios del liberalismo en cuanto a que el Estado no debía poner limitaciones al ejercicio de la libertad de los individuos.

También argumentamos que esta preferencia por un Estado con una acción social limitada mostraba a una Iglesia que se seguía considerando 
como la institución rectora de la sociedad en tanto su accionar incluía no sólo la vida terrena, sino que también la vida después de la muerte. El Estado, al centrarse sólo en los problemas terrenales, era una institución de rango menor, cobijada por la Iglesia. Por esto, sólo se aceptaba una intervención más directa del Estado en caso que el bien común resultara afectado severamente, como en el caso de las huelgas. Como otros autores ya han destacado para el caso de la evolución del derecho en el mismo período, el Estado se centró en ejercer un poder de policía más que de creación de derechos sociales de alcance universal (Bastías, 2015: 24; Yáñez, 2008: 105-113). Recién la Constitución de 1925 cambiaría esa situación al establecer que el Estado debía prodigar a "todos los habitantes de la República [...] un mínimo de bienestar, adecuado a la satisfacción de sus necesidades personales y a las de su familia" (Gobierno de Chile, 1925: 8 y 10-11). En efecto, la nueva carta magna representó el primer paso del lento -e inconcluso- proceso de establecimiento de un Estado de bienestar en Chile. Representó también un primer punto de llegada de las discusiones en el ámbito público que desde fines del siglo XIX se daban sobre la necesidad de un rol más activo del Estado (Bastías, 2015: 13). Como Collier y Sater han señalado, "la intervención estatal en los problemas laborales fue vista con creciente beneplácito por los intelectuales" (Collier y Sater, 1996: 209). ${ }^{2}$ Así, la discusión y aprobación de leyes sociales en este período se dio en un marco jurídico y cultural de transición entre un Estado que ejercía un "poder de policía" en la sociedad a uno que debía velar por el bienestar de todos los individuos en igualdad de condiciones (Bastías, 2015: 27).

Es en este período de discusiones donde el presente artículo se centra al estudiar el aporte católico al debate. Para ello, se comenzará haciendo referencia a los postulados de la encíclica Rerum Novarum sobre la intervención estatal y que daban sustento al pensamiento católico chileno sobre la materia. Luego se estudiarán las ideas de los arzobispos de Santiago del período, Mariano Casanova y Juan Ignacio González, sobre el rol del Estado desplegadas en sus cartas pastorales que se referían a problemas sociales. Estas ideas fueron profundizadas por sacerdotes de la jerarquía eclesiástica chilena, quienes en diversas instancias como conferencias y artículos en la prensa periódica explicaban los alcances que debía tener el trabajo estatal. Dos religiosos son los analizados en este artículo: Rafael Edwards y Martín Rücker. Finalmente, este pensamiento se reflejó también en la opinión de la Iglesia sobre las leyes sociales discutidas en este período, como la ley de habitación obrera aprobada en 1906 y la ley de descanso dominical de 1907.

2 Traducción propia. 


\section{El Estado según el Vaticano}

El Papa León XIII en su encíclica Rerum Novarum, publicada en mayo de 1891, afirmaba que cuando se rompía la armonía entre las dos clases sociales se producía, la Cuestión Social. ${ }^{3}$ Este quiebre, además, podía darse por problemas tanto en los sectores pobres como en los ricos. Eran situaciones todas donde la justicia distributiva se incumplía:

"si alguna vez ocurre que algo amenaza entre el pueblo por tumultos de obreros o por huelgas; que se relajan entre los proletarios los lazos naturales de la familia; que se quebranta entre ellos la religión por no contar con la suficiente holgura para los deberes religiosos; si se plantea en los talleres el peligro para la pureza de las costumbres por la promiscuidad o por otros incentivos de pecado; si la clase patronal oprime a los obreros con cargas injustas o los veja imponiéndoles condiciones ofensivas para la persona y dignidad humanas; si daña la salud con trabajo excesivo, impropio del sexo o de la edad" (León XIII, 1891).

La Cuestión Social, continuaba el Papa, solamente se remediaba mediante la práctica, de parte de ambos bandos, de los principios cristianos. Si bien reconocía la importancia del Estado como "entidad defensora de la comunidad y de sus miembros", recomendaba que debía entrometerse sólo cuando "se ha producido o amenaza algún daño al bien común o a los intereses de cada una de las clases que no pueda subsanarse de otro modo". Para el pontífice, la armonía social provenía de los principios cristianos, no de una legislación social. León XIII concebía al Estado como una estructura en grado inferior a la Iglesia, puesto que sólo la religión "puede grandemente arreglar entre sí y unir a los ricos con los proletarios, es decir, llamando a ambas clases al cumplimiento de sus deberes respectivos y, ante todo, a los deberes de justicia". Por ello, León XIII recalca que la acción estatal debe ser "dentro de ciertos límites [...] determinados por la misma causa que reclama el auxilio de la ley". Ello significaba que el Estado no debía actuar de un modo preventivo, sino que las leyes debían aparecer para subsanar un problema ya existente o para evitar un problema en ciernes. Ante todo, el Estado debía proteger los derechos individuales y con especial cuidado, aquellos de los sectores más pobres de la sociedad:

"en la protección de los derechos individuales se habrá de mirar principalmente por los débiles y los pobres. La gente rica, protegida

3 Los adelantos de la industria y de las artes, que caminan por nuevos derroteros; el cambio operado en las relaciones mutuas entre patronos y obreros; la acumulación de las riquezas en manos de unos pocos y la pobreza de la inmensa mayoría; la mayor confianza de los obreros en sí mismos y la más estrecha cohesión entre ellos, juntamente con la relajación de la moral, han determinado el planteamiento de la contienda (León XIII, 1891). 
por sus propios recursos, necesita menos de la tutela pública; la clase humilde, por el contrario, carente de todo recurso, se confía principalmente al patrocinio del Estado. Este deberá, por consiguiente, rodear de singulares cuidados y providencia a los asalariados, que se cuentan entre la muchedumbre desvalida" (León XIII, 1891).

No obstante, el "Papa de los obreros" advierte que, pese a la protección del trabajador, el Estado también debe velar por la inviolabilidad de la propiedad privada: "Intervenga, por tanto, la autoridad del Estado y, frenando a los agitadores, aleje la corrupción de las costumbres de los obreros y el peligro de las rapiñas de los legítimos dueños.

El Pontífice resumía diciendo que "las leyes no deberán abarcar ni ir más allá de lo que requieren el remedio de los males o la evitación del peligro". León XIII no consideraba al Estado como el organizador de los derechos y deberes. Si algún problema surgía, el Estado debía tomar alguna acción para proteger a los más débiles. Esta diferencia es importante, porque permite entender el cambio en el discurso de la Iglesia Chilena sobre la materia que veremos a continuación. Era, en el fondo, un asunto sobre cómo entender la organización de la sociedad. Al dejar al Estado en un lugar secundario, el Papa reafirmaba su postura de que la religión era la única y real solución a la Cuestión Social, puesto que "para acabar con la lucha y cortar hasta sus mismas raíces, es admirable y varia la fuerza de las doctrinas cristianas [que] puede[n] grandemente arreglar entre sí y unir a los ricos con los proletarios, es decir, llamando a ambas clases al cumplimiento de sus deberes respectivos $y$, ante todo, a los deberes de justicia." 4 Es por esto que las recomendaciones concretas de la Encíclica sobre cómo enfrentar los problemas sociales de los obreros no tienen relación con el Estado, sino con el actuar de laicos y religiosos: la fundación de patronatos, de sociedades de socorros mutuos y de sociedades de obreros (una nueva versión de los gremios medievales). Era lo que en encíclicas posteriores se denominaría la "Acción Social Católica".

\section{El Estado según la jerarquía eclesiástica chilena}

\section{La opinión de los Arzobispos Mariano Casanova y Juan Ignacio González}

La Iglesia chilena siguió los dictados del Vaticano. ${ }^{5}$ En la Pastoral en que dio a conocer la Encíclica Rerum Novarum en septiembre de 1891, el arzo-

4 La versión en inglés de esta frase de la Encíclica muestra mejor la postura de la Iglesia: "there is no intermediary more powerful than religion".

5 Una muy somera revisión de la recepción de las ideas de la Encíclica Rerum Novarum en Chile en Vergara, 2011. 
bispo de Santiago, Mariano Casanova, recogió los postulados del documento vaticano señalando que el Estado debía procurar "el bienestar general por medio de buenas leyes" que, por una parte, reprimieran "con mano severa los atentados contra la propiedad" o, por otra, ayudaran a "mejorar la condición de la clase proletaria protegiéndola contra las exacciones injustas y las exigencias inmoderadas de la codicia". Por eso, afirmaba Casanova, era necesaria la ley de descanso dominical en beneficio de los trabajadores. En otras palabras, las leyes sociales no tenían un carácter universalista, como empezaría a ser a partir de 1925, sino que serían para un sector específico de la población, los obreros. Por último, el arzobispo también señalaba que el Estado debía auxiliar a "que se guarde y fomente la religión y florezcan las buenas costumbres en la vida pública y privada" (Casanova, 1891).

Es por esto que en los documentos del prelado la participación estatal sólo se hace presente al tratar problemas específicos y siempre se trata de que el Estado fomente o promueva, pero nunca lleve a cabo la labor social. Eso está reservado para la Iglesia. Por ejemplo, en 1905 en su "Pastoral acerca de la necesidad de mejorar la condición social del pueblo" pasa revista al alcoholismo, la vivienda obrera, la educación de las clases populares y sólo hace referencia al Estado cuando apela al "fomento" estatal a la construcción de habitaciones obreras (Casanova, 1905: 426). El resto siempre es responsabilidad del católico, ya sea laico o religioso. Como es él quien debe hacer las labores sociales, Casanova no lo considera un actor de primera línea, sino que sólo accesorio. En la Pastoral de 1891, Casanova sólo hace una referencia tangencial al Estado cuando recomienda la formación de diversas sociedades de obreros para asegurar su bienestar, apelando a que no podía "el Estado estorbar su formación con leyes restrictivas de la libertad de asociación, no poniéndole otro límite que el que señalan la justicia, la moral y el bien público" (Casanova, 1891: 381). De manera similar, en su pastoral de 1889 sobre alcoholismo, Casanova deslizó -aunque no profundizó en el tema-que "los legisladores y todos los que tienen en el Estado la misión de promover los intereses públicos y procurar el bien social, deben arbitrar medidas eficaces para contener los estragos de la embriaguez" (Casanova, 1889: 152).

Juan Ignacio González, sucesor de Mariano Casanova en el Arzobispado de Santiago entre 1908 y 1918, si bien el foco de su labor social estuvo en el impulso que le dio a la "Acción Católica" y a las asociaciones de obreros, se refirió en forma más directa -aunque en menos ocasiones- al rol del Estado. En su pastoral de 1910 titulada simplemente "Sobre la Cuestión Social", González afirmaba: "Es obra propia de un buen Gobierno, es acción correspondiente a un Congreso verdaderamente democrático, hacer que la política converja al terreno social y económico en que deben resolverse los problemas que interesan a las clases trabajadoras" (González, 1910: 558). González va más allá de Casanova, comprendiendo que el Estado no sólo 
debe intervenir cuando la relación entre el rico y el pobre se ha deteriorado, sino que era responsabilidad de las autoridades políticas el establecer normativas que regularan esta relación puesto que el liberalismo no era suficiente:

"La rectitud y la justicia llevan la paz y el bienestar a todas partes; son el principal elemento de orden, y deben ser la regla invariable que informe el criterio de los gobernantes. Pero no bastan los buenos magistrados para dar a cada uno lo que es suyo; es además indispensable otorgar a los débiles ciertas garantías y ciertos auxilios, que los defiendan de los más fuertes en unos casos, y que, en otros, les proporcionen medios para conseguir lo que por sus esfuerzos individuales no podrían alcanzar" (González, 1910: 558).

En términos concretos, el arzobispo proponía en su pastoral de 1910 que el Estado pusiera sucursales de Cajas de Ahorros del Estado en cada ciudad o villa cabecera de departamento, haciendo especial hincapié de su importancia en el campo, de manera que al trabajador no le fuera difícil la práctica del ahorro.

\section{La opinión de los sacerdotes Rafael Edwards y Martín Rücker.}

¿Cómo se tradujo la visión de la Iglesia sobre el Estado al interior de ella? ¿Cómo hablaban sus representantes sobre el Estado? En esta sección me referiré a las opiniones sobre la intervención estatal para la resolución de los problemas sociales de dos sacerdotes miembros de la jerarquía eclesiástica chilena: Rafael Edwards y Martín Rücker. Los dos alcanzaron la dignidad episcopal y tuvieron un rol destacado dentro de la Iglesia en la creación y desarrollo de diversas actividades e instituciones en favor del obrero. Rafael Edwards (1878-1938) pertenecía a una de las familias más tradicionales del país. Pese a que fue un fuerte candidato a suceder a su primo en tercer grado, Crescente Errázuriz, en el arzobispado de Santiago, las fuentes vaticanas muestran que su avasallador carácter habría jugado en contra de sus pretensiones (Andes: 2014, 177). Y credenciales no le faltaban. Enviado por el Seminario de Santiago a Roma para terminar sus estudios sacerdotales en el Colegio Pío Latinoamericano, a su regreso a Chile desarrolló su labor eclesiástica en una multiplicidad de labores: fue profesor en el Seminario de Santiago, uno de los redactores permanentes de la sección de Estudios Sociales de la Revista Católica así como creador y director de varios periódicos católicos, orador cuasi permanente de las convenciones del Partido Conservador chileno donde se

6 La Caja de Ahorro, creada a mediados del siglo XIX, tenía por objeto fomentar el ahorro. Es el actual "BancoEstado" que, pese a depender del Estado, funciona bajo las mismas reglas y aplicando el mismo criterio a sus clientes que el resto de la banca chilena. 
refiere constantemente a la idea de la "democracia cristiana"; primer Obispo Castrense a partir de 1910 (debiendo viajar a distantes regiones del país como la región disputada con Perú en el norte de Chile luego de la Guerra del Pacífico y la Isla de Pascua en medio del océano Pacífico), actor determinante en las negociaciones diplomáticas sobre la separación de la Iglesia y el Estado en 1925, y director de la Acción Social Chilena desde principios de la década de 1920 hasta su muerte en 1938. Martín Rücker (1867-1935) fue uno de los más cercanos asistentes del arzobispo de Santiago José Ignacio González en las obras sociales de la arquidiócesis. Ambos se conocieron en la ciudad puerto de Valparaíso (donde Rücker nació y estudió para sacerdote) cuando González llegó a hacerse cargo de la Iglesia porteña. Fue Vicario en la ciudad norteña de lquique, donde presenció una de las más grandes matanzas de obreros a manos del gobierno, en diciembre de 1907. En Santiago, fue rector de la Universidad Católica entre 1915 y 1920, renunciando después de serias divergencias con el nuevo arzobispo, Crescente Errázuriz. Luego de un período en Europa, en 1926 fue designado Obispo de la nueva diócesis de Chillán, desempeñándose allí hasta su muerte en 1935.

Como sacerdotes, Edwards y Rücker desarrollaban una labor pública, pero dado que no fueron sólo párrocos, sino que ocuparon importantes puestos dentro de la jerarquía eclesiástica chilena, sus intervenciones públicas sobre la Cuestión Social adquieren relevancia. No se trata de sermones, sino que de conferencias ante obreros y estudiantes universitarios, artículos en periódicos y folletos, y presentaciones en congresos panamericanos. Ellos representan a la Iglesia tomando parte en los debates del momento, representan a la Iglesia en movimiento. El análisis de sus ideas muestra que el pensamiento social católico -y en este caso específico, en relación al Estado- pese a usar plataformas de difusión modernas como la prensa, se mantiene en su interpretación de una organización social jerárquica y que le da a la Iglesia un lugar rector en la organización social en desmedro del Estado.

Entre el 25 de diciembre de 1908 y el 5 de enero de 1909, Rafael Edwards participó en el "Cuarto Congreso Científico (Primero Panamericano)", celebrado en Santiago de Chile.7 Su presentación, en la sección "Ciencias Económicas y Sociales", se tituló "Necesidad de Institutos de Reforma Social como medida de preparar la legislación social obrera". Comenzaba

7 El "Congreso Científico" fue "la primera y más importante asociación científica internacional de América Latina al comienzo del siglo veinte". Se llevaron a cabo cinco versiones entre 1898 y 1916: Buenos Aires (1898), Montevideo (1901), Río de Janeiro (1905), Santiago (1908-1909) y Washington (1915-1916). Una idea original de la Sociedad Científica Argentina -aunque instituciones y personas públicas y privadas podrían participar-, los congresos tenían por objetivo poner el foco en el conocimiento científico por sobre las diferencias políticas entre los países americanos (Calvo, 2011: 87). 
identificando dos tipos de democracia: la política y la social. La primera se estableció, argumentaba el sacerdote, cuando se produjo la independencia de los países latinoamericanos y su posterior formación republicana. Esta democracia aseguraba la "libertad pública". Sin embargo, la realidad del momento -a casi un siglo de producida la independencia- era que no todos los habitantes del país, para el caso chileno, podían practicar dicha libertad, condición esta última para la existencia de una democracia social. Esta democracia social aseguraría "la elevación y el bienestar a las multitudes trabajadoras que son el mayor número entre los ciudadanos y forman la base de la prosperidad". Destaca Edwards que el fin último de la democracia estaba en el pueblo, pues "la aspiración sinceramente democrática es que la grandeza de nuestras repúblicas se verifique en el pueblo y por medio del pueblo" (Edwards, 1911: 143). ${ }^{8}$

En este proceso de evolución hacia una democracia social, es decir, completa, sostenía Edwards, el Estado tenía un papel fundamental puesto que éste "a más de defender todos los derechos ha de promover la prosperidad pública" y ella no podía alcanzar a "los más números y débiles" de la población, si estos no tenían un nivel mínimo de bienestar (Edwards, 1911: 143-144). Edwards advierte que su postura se podría interpretar como un apoyo al "socialismo de Estado" que en Chile era ardientemente promovido por el Partido Radical (Cruzat y Tironi, 1987). Sin embargo, el joven sacerdote, que recién había cumplido treinta años, afirmaba: "¿qué nos importan los adjetivos cuando se trata de reparar las injusticias y de contribuir a la felicidad de las multitudes trabajadoras?" (Edwards, 1911: 144).

Luego de establecer el diagnóstico, Edwards se concentró en desarrollar su idea principal sobre cómo el Estado debía asegurar el bienestar de las clases obreras. "El Estado no puede permanecer impasible ante la situación dolorosísima en que se encuentran hoy día las multitudes", afirmaba, señalando además que las miserias de los trabajadores eran tanto económicas como morales. Apelaba a que el problema no debía enfrentarse sólo con teorías o con una "política de ocasión" que no tomaran en cuenta o desconocieran

8 Este contrapunto entre una democracia política y una democracia social ha sido recogido por la historiografía, aunque no con las mismas denominaciones. Mario Góngora señala que durante el siglo XIX predominó el "liberalismo político" o también llamado "ethos republicano" puesto que el país se concentró en la independencia y posterior construcción de la república. Con el surgimiento de la Cuestión Social hacia fines del siglo y sobre todo a principios del siglo XX, y con la consiguiente demanda de justicia social y el desarrollo de los movimientos de masas, se pasa a un período dominado por lo social y lo económico. En este período, identificado por Góngora entre 1915 y 1935, los "caudillos tribunicios" (Arturo Alessandri y Carlos Ibáñez) que llegaron al poder elaboraron "una legislación laboral orientada por el socialismo de cátedra o socialismo de Estado de origen alemán, que se oponían a la vez a los intereses oligárquicos" (Góngora, 1985: 36). 
la realidad del país. Tampoco se debía actuar en reacción al miedo causado por las manifestaciones violentas de algunos trabajadores, sino que debía ser una acción sincera e inspirada en la "justicia y caridad social". Por ello, las autoridades políticas debían tomar en cuenta no sólo las condiciones de vida y laborales de los trabajadores, sino que también sus aspiraciones y luego estudiar las soluciones más prácticas y además vigilar que las resoluciones tomadas sean eficazmente cumplidas. Estas cuatro condiciones configuraban el objeto de la propuesta principal de Edwards: los "Institutos de Reforma Social, Oficinas o Departamentos Nacionales del Trabajo". Con una oficina en cada provincia del país, su rol debía ser mucho más que el de una oficina de estadística, su trabajo principal debía ser el de preparar la legislación social basado tanto en "el conocimiento práctico de las necesidades de cada país", como en las experiencias de otros países. Este último punto era de mucha importancia para Edwards, pues consideraba que la coordinación de las legislaciones sociales entre los diversos países americanos ("legislación internacional" la define) aseguraba que ningún país quedara en desigual condición frente al resto. Según Edwards, los países que establecieran legislaciones sociales experimentaban un alza en el costo de producción, lo que podría beneficiar a los países que decidieran no legislar sobre el trabajo obrero, puesto que podrín vender más barato su producción. Por ello, proponía que esta coordinación panamericana se corporizara en la creación de una "oficina central" con sede en Washington, Estados Unidos (Edwards, 1911: 145).

La iniciativa de Edwards era novedosa en cuanto llamado internacional, pero en Chile desde 1907 existía una agencia estatal que se ajustaba en sus principales atribuciones a lo señalado por Edwards para los Institutos de Reforma Social. La Oficina del Trabajo fue creada en 1907 por decreto supremo (aunque también había un proyecto discutiéndose en el Congreso). Aparte de su trabajo estadístico, la Oficina debía "emprender cualquier otra investigación que crea conveniente encomendarle el Gobierno sobre la materia", es decir, el trabajo industrial (Yáñez, 2003: 169). El llamado de Edwards tal vez se debía a que la Oficina no contó en sus primeros años con un grupo de funcionarios que le permitiera llevar adelante todas las tareas encomendadas. Al momento de su creación tenía sólo dos funcionarios y en 1911 su dotación había aumentado a sólo cinco personas (Yáñez, 2003: 169).

Lo que sí es muy extraño es que Edwards haya escrito un texto como éste, en que propone medidas tan concretas sobre legislación social y el rol del Estado, puesto que, en otros textos y conferencias, el sacerdote se focaliza en las actividades de la Iglesia en favor del obrero. Es más, en ellos Edwards no habla de "democracia social" para referirse al mejoramiento del bienestar del pueblo, sino que de "democracia cristiana", la cual identifica como la solución definitiva a la Cuestión Social. Por ejemplo, en 1898, con solo veinte años y recién ordenado sacerdote en Roma, Edwards tradujo al español el 
texto del sociólogo italiano Guiseppe Toniolo La verdadera democracia. En la introducción de ese texto, Edwards señala:

"Nuestros programas políticos siguen adornándose con las viejas fórmulas de Libertad de imprenta, Libertad electoral, Libertad de reunión, Protección a la industria nacional, Igualdad ante la ley, y otras vanas frases que expresan derechos definitivamente adquiridos, que nadie niega, que nadie se atreve ni siquiera a discutir, que están irrevocablemente incorporados en la legislación y las costumbres. Tan excusados y añejos son esos artículos de programa, tan conquistadas y reconocidas están todas esas aspiraciones de otros tiempos, que se ven escritas en la bandera de todos los partidos, de tal manera que si quisiéramos distinguirlos por ellas, tendríamos que confundirlos a todos en uno solo [...] el problema de hoy es precisamente imponer la noción de la verdadera democracia, de la democracia cristiana, y enderezar hacia ella, que es el bienestar y la salvación, la reforma social que amenaza ser la ruina y la muerte" (Edwards, 1898: 5-7).

Más aún, su presentación en el Congreso Panamericano destaca también por la ausencia casi completa del aspecto religioso. En una primera lectura, la singularidad del texto pueda deberse a la audiencia ante la cual fue presentado. Se trataba de un "Congreso Científico" que reunía a intelectuales y pensadores en general, era un "evento reservado para minorías ilustradas (letradas)" (Calvo, 2011: 89). En efecto, sólo hacia el final de su presentación, Edwards proclamó: "Hace veinte siglos mi Maestro, al ver reunida a sus pies la inmensa muchedumbre ávida de consuelos, de amor y de justicia, dirigió al pueblo una mirada de infinita caridad y exclamó: Misereor super turbam. Me compadezco de las muchedumbres" (Edwards, 1911: 144). Eso era, concluía, lo que el Estado debía hacer para enfrentar la Cuestión Social: "Estas otras multitudes, que se agrupan a nuestra vista y que constituyen el gran proletariado americano, están sedientas también de consuelos, de amor y de justicia..." Aunque pueda deberse a la naturaleza del Congreso (otros temas tratados fueron, por ejemplo, la política monetaria en la región, el establecimiento de Cajas de ahorros, y el "socialismo intervencionista"), es destacable que Edwards no haya realizado ninguna alusión al rol de la Iglesia en la promoción de la democracia social, tomando en cuenta, además, que Edwards se desempeñó durante gran parte de su carrera como encargado de las actividades sociales de la Iglesia, que poco a poco se institucionalizarían bajo la denominación de "Acción Social Católica" y que se presentaba como la concreción de iniciativas de laicos dirigidos por sacerdotes, es decir, proyectos particulares, en favor del obrero.

Martín Rücker, por su parte, no se dedicó en ninguno de sus artículos o conferencias a tratar el tema del Estado en forma exclusiva, como lo hizo 
Edwards en 1908, pero sí dedicó espacios importantes al tema en algunas de sus intervenciones públicas, la mayoría de las cuales las realizó en la década de 1910 y se centraban en las ventajas de la Acción Social Católica. Hacia 1913, cuando refutó las ideas del socialista Luis Blanc sobre el derecho al trabajo, señaló que el fin del Estado era triple: protección del orden jurídico, fomento del bien común, y tutelar la moralidad pública. Se trata, como observa Bastías, del poder de policía de la autoridad. Pues Rücker recalca que el Estado estaba en obligación de ayudar a los individuos "sólo en el caso de que viniera un daño público [...] porque a él le toca velar por el bien común", no por el bien de las personas en forma individual (Rücker, 1913: 29). Es por ello que se comprende la intervención estatal en, ejemplifica Rücker, el caso de las huelgas que son el ejemplo máximo del rompimiento de la armonía entre ricos y pobres. Por ello, el Estado puede intervenir para terminar una huelga puesto que a él "le corresponde prevenir y resolver las colisiones que surgen entre los derechos de los individuos" (Rücker, 1915b: 26).

El Estado interventor que identifica Rücker es característica de, como señala en otro de sus artículos, una de las tres tendencias del socialismo, el "socialismo político reformista". ${ }^{9}$ Al contrario de lo que hizo Rafael Edwards en el Cuarto Congreso Panamericano al no temer ser identificado como simpatizante del "socialismo de Estado", Rücker lo deslegitima por completo, advirtiendo que esta "fe absoluta" en la acción estatal significaría que "el Estado [...] en manos socialistas protegerá al socialismo y hará la obra del socialismo" (Rücker, 1913: 32). Advierte, finalmente, que partidos políticos de esta tendencia se habían creado ya en Francia, Alemania, Bélgica, Holanda y Suiza.

En textos sobre otros problemas obreros, Rücker deja entrever esta posición. Cuando es preocupación por el bien común, el Estado está bien, como en el caso de la necesidad de legislar sobre el establecimiento de un salario mínimo (Rücker, 1913: 73-78), pero para el caso de la habitación obrera, la labor del Estado es vigilar y examinar la salubridad de las casas, y aunque "bueno es todo lo que hacen las autoridades públicas en orden de mejorar la situación del hogar obrero, [...] no menos bueno es lo que alcanza a hacer la iniciativa individual" (Rücker, 1913: 81).

Rücker también se refirió a la necesidad de una legislación social en una conferencia sobre la acción social ante estudiantes de leyes en la Universidad Católica a mediados de la década de 1910. En la ocasión afirmó que hablar

9 Las otras dos tendencias que Rücker identifica son el "socialismo político intransigente" que propugnaba la destrucción del Estado, y el "socialismo gremial" que postulaba que el Estado se autoeliminaría una vez que el proletariado se levante contra la opresión (Rücker, 1913: 33-34). 
de intervención estatal en asuntos sociales era un tema sensible porque era muy fácil caer en alguno de dos errores opuestos: el individualismo (no intervención del Estado) o en el socialismo (poder absoluto del Estado). Rücker aceptaba una "intervención legal, sabia y prudente" para prevenir que los obreros estuvieran indefensos ante empleadores que, coincidiendo con el Arzobispo González, "no siempre saben inspirarse en los principios de la justicia" (Rücker, 1917: 48). Dado que en la relación antagonista que se daba entre el capital y el trabajo los trabajadores eran siempre los más desfavorecidos, la legislación social era necesaria. Esta legislación incluía: "las condiciones higiénicas en que deben funcionar los centros fabriles, las horas de labor, los accidentes del trabajo, el seguro sobre la vida, el trabajo de las mujeres y niños, la faena nocturna, el descanso dominical, las cajas de crédito y las cajas rurales, las habitaciones obreras". Sin embargo, no detallaba si el Estado debía hacerse cargo de la creación e implementación de estas medidas o sólo crear normativas para ellas.

Que la legislación social fuera entendida para los más desfavorecidos ("la carencia de legislación es una desgracia para el pobre", Rücker, 1917: 49) significa que aún, como la gran mayoría de la clase política chilena del período, actuaba dentro de parámetros liberales y no con una concepción de derechos universales (Bastías, 2015: 24; Yáñez, 2008: 105-113). Por tanto, era una concepción del Estado que debía intervenir cuando el pobre no podía hacer uso de su libertad, pero no podía intervenir si ello significaba evitar la libertad de otros. En otras palabras, la acción del Estado debía ser después de que los problemas surgieran, no era algo consustancial a la naturaleza del Estado, como sí lo establecería la Constitución de 1925.

El papel limitado del Estado tenía su razón en que la institución rectora en una sociedad, y por tanto, anterior al Estado, según Rücker, era la Iglesia. En una conferencia dada ante la sociedad obrera "Centro Andacollo", titulada "La Iglesia y el Obrero", el sacerdote afirma que es la Iglesia la que, cumpliendo su tarea de "tutelar el bienestar del pueblo", le hace ver al Estado que el objetivo del trabajo estatal es "promover la felicidad temporal de los gobernados y la prosperidad pública, mediante el imperio de las leyes" (Rücker, 1914: 54). Es la iglesia la que pide al Estado actuar en favor del obrero, cuidarlo de la amenaza de los empleadores que los explotan, y que insta a las autoridades políticas la creación de Cajas de Ahorros para los obreros y que ellos no sean objeto de cargas impositivas excesivas en los artículos de primera necesidad.

Es por ello que Rücker le adjudica, al igual que Casanova, un rol accesorio y no protagónico al Estado, e identifica solamente a la Iglesia como la institución capaz de solucionar la Cuestión Social. En la conferencia "Bosquejo de un programa de Acción Social Católica" en la Asamblea Social de LlayLlay, Rücker señalaba que la única solución efectiva es la propuesta por la 
Iglesia y que ella consistía en fomentar el espíritu de asociación mediante la fundación de sociedades de socorros mutuos (Rücker, 1914: 153-154). En otra conferencia, esta vez en la tercera Asamblea General de la Unión Nacional, celebrada en la ciudad de San Felipe, vuelve a darle el protagonismo a la Iglesia, pero esta vez incluye al Estado, a través de la legislación social, como uno de los tres medios de la "Acción Católica", siendo los otros dos la iniciativa privada y las ya mencionadas asociaciones obreras católicas, puesto que, afirmaba el sacerdote, el derecho de asociación es fruto del derecho natural (Rücker, 1915a: 174-175 y 177). Finalmente, en una conferencia dada en la Universidad Católica sobre el peligro de las huelgas ante un grupo de obreros, Rücker se explaya en cómo el Estado debe ayudar, en un papel inferior, a la Iglesia: "Procure el Estado cooperar a la obra de la Iglesia y promover por todos los medios la práctica de la moral cristiana y de una educación basada sobre principios de rectitud y de Religión" (Rücker, 1915b: 27).

\section{Las leyes sociales y la Iglesia}

La Iglesia se mostraba como la única institución capaz de resolver la Cuestión social, aunque ello, como hemos visto hasta ahora, no significaba no considerar al Estado como un agente importante en su resolución, pero sí le dejaba un rol menor. De esta manera se comprende la opinión del mundo católico chileno en los debates sobre los proyectos de ley que desembocaron en las primeras así llamadas "Leyes Sociales". Por ejemplo, Alejandro Huneeus, miembro del Partido Conservador y quien fuera uno de los promotores de la ley de descanso dominical en el parlamento como veremos más adelante, presentó un trabajo sobre legislación social en el Primer Congreso Eucarístico de 1904 en la Sección de Obras Sociales. ${ }^{10}$ En las conclusiones se reconocía la existencia del problema obrero y se delimitaba los roles del Estado y de los católicos: "El Estado debe velar de un modo especial por la defensa de los derechos e intereses morales, intelectuales y económicos de los obreros, y se hace necesario, por consiguiente, que se dicten las que se llaman propiamente Leyes Sociales" (PCE, 1905: 620-621). Los católicos, en tanto, debían "tener un programa sobre legislación del

10 Los Congresos Nacionales Eucarísticos empezaron en Francia a mediados del siglo XIX a iniciativa de Emilia Tamisier, laica. El foco en la Eucaristía apuntaba a enfatizar la necesidad de renovar la fe en Cristo para enfrentar la ignorancia religiosa y el indiferentismo. Esto significaba que la devoción al sacramento de la Eucaristía debía ser promovido no solamente en misa, sino que también fuera de ella, y así es como los Congresos emergieron como la perfecta herramienta para ello. Hacia finales de siglo, las reuniones habían obtenido aprobación vaticana. En Chile, el primer congreso fue realizado en 1904 y se centró en la principal preocupación de los católicos de ese tiempo: la Cuestión Social (Saranyana, 2002: 69-70). Primer Congreso Eucarístico será citado en adelante como PCE. 
trabajo" que diera cuenta tanto de las ideas generales como de las reformas más urgentes. El resto de la propuesta se centraba en lo que los católicos debían "exigir y obtener del Estado": que se respetara la constitución cristiana de la familia; que se consagrara el derecho de cumplir con los deberes religiosos; que se defendiera "de un modo especial la vida e intereses de los obreros de los peligros a que por su condición se hallan expuestos"; que se respetara la libertada de asociación; que se prohibieran los juegos de azar; y que la autoridad política, en todos sus niveles, en las empresas e industrias que dependieran de ella, hiciera "cumplir y que cumplan sus deberes de patrones" (PCE, 1905: 621-622). De todos estos puntos, sólo el tercero y el sexto tenían relación directa con legislación social. En suma, lo que estaba en el debate era la naturaleza de la intervención estatal en la resolución de la Cuestión Social como se aprecia en las opiniones de religiosos y laicos sobre dos de las más emblemáticas "Leyes sociales" del período que estudiamos: la ley de habitación obrera de 1906 y la ley de descanso dominical de 1907.

\section{La ley de habitación obrera, 1906}

En Chile, como era la norma en los países que experimentaron la Cuestión Social, los problemas sociales comenzaron a derivarse de la migración de trabajadores de las zonas rurales a las ciudades (Santiago, Valparaíso y Concepción principalmente) o hacia las ciudades mineras en el norte del país donde se extraía salitre. Las estadísticas muestran que, para el caso de Santiago, la capital chilena pasó de tener 80.000 habitantes en 1843, a contener 129.807 personas en 1875. Tan sólo veinte años después, en 1895, ese número se duplicó, llegando a 256.403. Ya en 1920, el censo reportaba la existencia de 507.000 santiaguinos (De Ramón, 1992: 221). Por su parte, Santiago necesitaba trabajadores. Desde mediados del siglo diecinueve, aumentó la oferta de trabajos en el sector de obras públicas en virtud de la construcción de caminos y canales de irrigación, pero también se necesitaban trabajadores para los sectores agrícolas aledaños a la ciudad para producir alimentos para la creciente población (De Ramón, 1992: 224). Adicionalmente, hacia 1906, Santiago tenía 1.100 industrias, que representaban el $40 \%$ del total nacional. El crecimiento de la ciudad provocó que el gobierno, hacia finales del siglo XIX, decidiera la creación de una nueva jurisdicción territorial, las comunas, más pequeñas que las provincias (Walter, 2005: 10).

Pese a que esta última disposición trajo como consecuencia el crecimiento del área habitable de la ciudad (Walter, 2005: 8), las condiciones de vida para la población mayoritaria -los sectores populares- eran deplorables. La vivienda típica era el denominado "conventillo", construcción que consistía de un largo pasillo y muchas, pequeñas y oscuras habitaciones. El pasillo era usado como cocina y lavandería y debido a que no había sistema de 
alcantarillado, también era donde se desechaban las aguas sucias. No había baños y los arriendos eran altísimos, muchas veces cayendo en la usura. En cada habitación vivía una familia, generalmente compuesta de cinco o más personas (Vial, 1981: 500). Hacia 1911, el 40\% de la población de Santiago vivía en conventillos (Walter, 2005: 14). El hacinamiento facilitaba la propagación de enfermedades como la viruela que, entre población con mala alimentación como los sectores populares, tenía una altísima mortandad. ${ }^{11}$

El problema de la habitación obrera fue una de las principales preocupaciones en el debate público sobre la Cuestión Social. A la evidencia concreta del problema que se apreciaba en los barrios de una ciudad que no tenía la segregación territorial de la actualidad, se sumaban iniciativas estatales desde mediados del siglo XIX que daban cuenta del interés de la autoridad por cuidar la salubridad de la ciudad. ${ }^{12}$ Era, una vez más, el poder de policía. Y este poder de policía fue el que se hizo presente en el debate en el origen de la ley de habitaciones obreras promulgada finalmente en 1906. Cuando surgieron las primeras ideas de legislar sobre la materia, en 1900, se dio un debate sobre el rol del Estado en la construcción de las habitaciones obreras. ¿Debía construir el mismo Estado con fondos públicos o debía apoyar la iniciativa privada? El proyecto del diputado Manuel Rivas Vicuña, del Partido Liberal, proponía lo primero, en tanto que el proyecto que presentó el gobierno y el que finalmente se acogió a discusión y derivó en la ley de 1906, daba al Estado un rol secundario, de apoyo a diversas iniciativas privadas (Yáñez, 2003: 166). Aun así, la ley aún es señalada en la historiografía como el inicio de la política asistencial en relación a la vivienda (Hidalgo, 2000). La nueva normativa estableció la creación del Consejo de Habitaciones Obreras, cuyo objetivo era promover la construcción de casas higiénicas para los obreros. También entregaba especificaciones sobre el mejoramiento o demolición de edificios que no cumplían con las condiciones higiénicas básicas y regulaba el rol de compañías privadas en la construcción de nuevas casas. Sólo de forma excepcional, se autorizó al Presidente de la República la inversión de hasta 600.000 pesos en la construcción de viviendas (Yáñez, 2003: 167). En general, la ley tuvo alguna efectividad en el control de los conventillos, pero la construcción de nuevas casas fue una meta muy difícil de materializar (Hidalgo, 2000).

11 La peor epidemia de viruela en Chile fue en 1872, que dejó un saldo de 6.344 muertos, de los cuales 4.328 eran de Santiago. En otra epidemia de 1876, murieron 6.324, y 5.710 de ellos eran de la capital, lo cual representaba un $4 \%$ de su población. Hubo otros brotes en 1898, 1903, 1904, 1905 y 1909. Ver Droguett (2010: 30-31) y Grez (2010).

12 Un buen estudio sobre las reglamentaciones legales sobre la habitación obrera en Chile en Hidalgo, 2000. 
Una de las construcciones realizadas por el Estado fue la "Población Huemul", un proyecto de la Caja de Crédito Hipotecario y construida en 1911. Comprendía 166 casas en el suroeste de Santiago y constituyó uno de los primeros barrios industriales en Chile (Hidalgo, 2002: 95; Hidalgo, 2000). La Revista Católica le dedicó un largo artículo con ocasión de la inauguración del conjunto habitacional a la que el autor del texto asistió. Describe las casas y el barrio y el mecanismo por medio del cual los trabajadores podían convertirse en propietarios de las casas. En este aspecto, felicitaba el fomento del ahorro de los obreros que realizaba la Caja de Crédito Hipotecario. Al contrario de los conventillos, "verdadera cloacas morales y físicas" (La Revista Católica, 1911: 478), las nuevas casas eran higiénicas, espaciosas y con abundante luz natural. Sin embargo, para el autor el beneficio principal de las nuevas viviendas era la reforma de los hábitos y costumbres de las familias obreras. Observa que, al convertirse en propietarios, los obreros también devendrían en personas "sobrias y trabajadoras". Además, el nuevo estatus de ser dueño de un bien raíz haría que el trabajador sea "refractario a las ideas antisociales que se le predican". Finalmente, los obreros adquirirían "hábitos de higiene y limpieza [porque] es imposible que no sea aseado quien viva en algunas de las casitas de la Población Huemul" (La Revista Católica, 1911: 478-479). Para la publicación eclesiástica, como además se apreciaba en otras opiniones de la Iglesia sobre la Cuestión Social, la pobreza era condición sine qua non de vicios y problemas morales.

Pese a las felicitaciones, lo que mejor le acomodaba a la Iglesia era el fomento a la iniciativa privada que establecía la ley. Aunque la ley no incluía financiamiento para las iniciativas (Yáñez, 2003: 185), sí se constituyó en el establecimiento de las reglas del juego para la construcción de viviendas populares por privados. En su pastoral de 1905 sobre los problemas sociales del país y cuando el proyecto de ley se discutía en el Congreso, el arzobispo de Santiago afirmó que "Es un consuelo el observar que ya se piensa en poner algún remedio a esta pública necesidad, preocupándose las autoridades de las habitaciones para obreros" (Casanova, 1905: 425; La Revista Católica, 1911: 523-524). Pero lo que Mariano Casanova alababa más en su pastoral de 1905 eran las iniciativas privadas de construcción de viviendas obreras, que existían desde antes de la ley de 1906. Un ejemplo es la "Institución León XIII", fundada en 1891 por el laico Melchor Concha y Toro. Esta institución, Casanova afirmaba, tenía "resultados benéficos[...], gozando sus habitantes de comodidades antes no conocidas" (Casanova, 1905: 425). La organización tenía un consejo de tres personas (un eclesiástico, un miembro de la familia Concha y un oficial municipal), y tenía por objetivo construir casas para trabajadores y arrendárselas a un precio más barato de lo normal. Como el Estado haría con la ley de 1906, la institución planeaba que luego de un período de arriendo, los arrendatarios pudieran convertirse en propietarios (Hidalgo, 
Errázuriz, y Booth, 2005). Para ello, las familias debían cumplir con ciertos requisitos que la ley no consideraba: debían probar un comportamiento de acuerdo a la moral. Las primeras veintisiete casas fueron finalizadas en 1894 y otras doce fueron construidas dos años después.

La "Institución León XIII" recibió a lo largo de su existencia un fuerte apoyo de la Iglesia. Además de las palabras aprobatorias de Casanova, La Revista Católica también aplaudía la iniciativa laica y privada. El artículo principal de la edición de la revista del 17 de agosto de 1912, cubrió la celebración del vigésimo aniversario de la institución, ceremonia a la que asistió el Presidente de la República, Ramón Barros Luco. La revista presentaba una breve historia de la organización, observando que este tipo de obras eran "prueba elocuente de los recursos infinitos que tiene la Iglesia para la curación de todos los males sociales" (La Revista Católica, 1912: 299). La institución, se concluía, había sido el ejemplo para la ley de 1906, por tanto "a ella corresponden los honores del triunfo" (La Revista Católica, 1912: 3000). La institución había recibido incluso el beneplácito papal (La Revista Católica, 1913: 500).

Otra institución religiosa anterior a la ley de 1906 fue la "Sociedad de Instrucción y Habitaciones para Obreros", fundada en 1904 por el futuro arzobispo Juan Ignacio González, los sacerdotes Juan Francisco Fresno, José Horacio Campillo y los laicos Fernando Irarrázaval, Alejandro Larraín y Pedro Infante. Su objetivo era crear no sólo barrios obreros, sino que también entregar educación y servicios religiosos a los trabajadores. Hacia 1919, había construido ochenta casas, cuatro establecimientos educacionales, un patronato y un círculo de obreros (Hidalgo, Errázuriz y Booth, 2005).

La Revista Católica constantemente publicaba algunos de los decretos sobre la institución y cubría sus asambleas anuales y ceremonias (ver, por ejemplo, La Revista Católica, 1906: 889-890; 1906: 13; 1906: 783-786; 1912: 77-79; y 1929: 1091-1097). En 1910, el redactor de la sección "Acción Social" destacaba que el proyecto habitacional de la Sociedad contribuía a liberar a los obreros del conventillo, que era "causa de la degeneración física y moral de nuestro pueblo" (La Revista Católica, 1910: 456). También se felicitaba que las obras fueran desarrolladas por laicos, es decir, el sector privado. "Debemos mirar con cariño e interés una sociedad que es orgullo de la iniciativa católica y particular", decía el columnista de La Revista Católica en su reporte sobre la sexta asamblea de la Sociedad de Instrucción y Habitaciones para Obrerosen 1912 (La Revista Católica, 1912: 79). Siete años después, la revista felicitaba otra vez el trabajo de esta institución en una tarea (la habitación obrera) que demandaba "que las iniciativas particulares completen la obra del gobierno" (La Revista Católica, 1919: 552).

Es por esto que la Iglesia encajó tan bien en la nueva ley, ya que como institución tenía una mayor capacidad de movilización en este aspecto porque 
ya tenía la maquinaria para movilizar recursos en obras sociales. El Estado, al contrario, no actuaba como realizador, sino como facilitador para que otros hicieran ejercicio de su libertad.

\section{La ley de descanso dominical, 1907}

A diferencia de la ley sobre habitaciones obreras, la ley de descanso dominical no tenía que ver con realizaciones concretas en pro del obrero, sino que con reglamentar su trabajo, era una medida intangible. Era algo de lo que no se podía hacer cargo la Iglesia, como sí lo hacía con las viviendas. Pero también era importante para la Iglesia en términos espirituales, pues el trabajador necesitaba un día libre de trabajo a la semana no sólo para reparar fuerzas, sino que también para ir a la Iglesia, por lo que idealmente ese día libre debía ser el domingo. De hecho, en 1892, Mariano Casanova dedicó una de sus más largas pastorales a la "santificación del domingo". En casi treinta páginas, el arzobispo criticaba la codicia de los patrones que violaban la libertad de los trabajadores de cumplir con sus deberes religiosos al forzarlos a trabajar sin un día de descanso a la semana. Esto traía como consecuencia, a su vez, que los trabajadores no aprendieran sobre obediencia a la autoridad y así tampoco aprenderían a respetar la autoridad política (Casanova, 1892: 241). Casanova menciona los ejemplos de Alemania, Inglaterra y Estados Unidos que ya tenían leyes sobre descanso dominical con el objetivo de prevenir desórdenes sociales. Así, hacía un llamado a las autoridades municipales para que dieran el ejemplo "no autorizando jamás los trabajos públicos en los días festivos" (Casanova, 1892: 252).

Pese al llamado de Casanova, el interés por legislar sobre la necesidad de descanso de los trabajadores de un día a la semana apareció recién en 1901, en el proyecto de legislación laboral presentado por Malaquías Concha, diputado por el Partido Radical. En agosto de 1903 y junio de 1904, adicionalmente, hubo protestas públicas de asociaciones de trabajadores en Santiago y Valparaíso respectivamente, exigiendo una ley de descanso dominical (Yáñez, 2008: 146). Durante la movilización de 1903, el 4 de agosto, el diputado del Partido Conservador Alejandro Huneeus, presentó un proyecto de ley específico sobre la materia. Usando la palabra "santificación" para la necesidad de no trabajar los domingos, Huneeus hablaba en su proyecto sobre el origen religioso del descanso dominical, destacando que era una medida promovida también por el Papa León XIII. En otras palabras, seguía los principales argumentos de la Pastoral de Casanova de once años antes. Pero también Huneeus añadía que el descanso dominical era un deber de justicia y caridad de los empleadores (Biblioteca del Congreso Nacional de Chile, 5).13

13 Biblioteca del Congreso Nacional de Chile será citada en adelante como BCN. 
Con ocasión del Proyecto de Huneeus, La Revista Católica publicó un largo artículo que reproducía algunos párrafos de la pastoral de Casanova. El editor alababa la moción del diputado conservador y observaba la importancia de tener tal "ley civil" porque el descanso dominical, afirmaba, había sido ya establecido "por la ley eclesiástica y civil". El autor también notaba que "De todas partes de la República se ha levantado un clamor de aprobación y de aplauso" (La Revista Católica, 1903: 243).

En 1904 también, el 25 de noviembre, Juan Walker Martínez, ex diputado y militante del Partido Conservador expuso sobre la santificación de los días festivos en la quinta sesión de la sección "Obras Eucarísticas" del Primer Congreso Eucarístico. Su presentación fue aprobada unánimemente por los miembros de la sección. De sus quince conclusiones, hubo tres específicamente sobre el descanso dominical. La primera decía que los católicos debían promover que el gobierno y el parlamento aprobaran la ley de descanso dominical de acuerdo al tercer mandamiento (PCE, 1905: 439). La segunda sugería no apoyar negocios que trabajaran en días festivos o domingos si no había necesidad imperiosa para ello. Proponía que para controlar la observancia de la medida, se tuviera en las iglesias un libro de registro donde comerciantes, hacendados, jefes de taller y trabajadores en general que prometieran observar el descanso dominical pudieran firmar (PCE, 1905: 439-440). La última conclusión promovía la fundación de una asociación católica responsable de llevar a cabo las dos primeras propuestas. El trabajo de dicha asociación podría realizarse en conjunto con otros grupos similares, no importando si eran católicos o no confesionales (PCE, 1905: 441). En el trabajo de obligar a las personas a cumplir con la normativa no se incluía al Estado.

El Proyecto de ley de Huneeus permaneció en el parlamento chileno un par de años hasta su aprobación y promulgación en 1907. En el intertanto, en 1905 y 1907, La Revista Católica publicó las leyes sobre descanso dominical de España y Estados Unidos (La Revista Católica, 1904: 58-59; 1905: 234-235 y 813-818). Sobre este último caso, el editor afirmaba que esperaba que "los que opinan que sólo en los pueblos decadentes se santifican los domingos" notaran el ejemplo norteamericano (La Revista Católica, 1905: 234).

La ley finalmente se promulgó el 29 de agosto de 1907. Estipulaba que "empresas de cualquier especie, públicas o privadas, [...] darán un día de descanso a los individuos que hayan trabajado todos los días hábiles de la semana". La ordenanza era obligatoria e irrenunciable para mujeres y menores de dieciséis años de edad. Contra los deseos de la Iglesia, la ley no estableció la obligatoriedad del día domingo como descanso, sino que cualquier día de la semana dependiendo del tipo de trabajo, aunque fue conocida como "ley de descanso dominical". La ley también mandaba que los trabajadores no debían laborar el 1 de enero, el 18 y el 19 de septiembre, 
y el 25 de diciembre. La multa por no cumplir con la ley debía ser pagada en la municipalidad del empleador y cualquier persona podía denunciar el incumplimiento de la ley (BCN, 95-96).

La Revista Católica publicó la ley en sus páginas, pero no hizo comentarios sobre ella (La Revista Católica, 1907: 393-394). ¿Por qué el aparente poco interés? ${ }^{14}$ Tal vez porque el descanso dominical fue una de las leyes sociales que causó menos debate en la clase política puesto que había consenso sobre la necesidad de tal normativa ya que representaba la necesidad de intervención estatal ante la amenaza al bien común. Así lo demuestra la discusión en la Cámara de Diputados del proyecto de Huneeus. El diputado radical Malaquías Concha declaraba:

"El Papa León XIII que, como se sabe, ha sido llamado el Papa de los obreros, por cuanto se preocupó mucho de ellos durante su apostolado, recomienda en su notable encíclica Rerum Novarum, el descanso dominical y nosotros a título de este espíritu de libertad, ¿habremos de rechazar esta institución del descanso dominical, tan benéfica para la humanidad, nada más que porque viene del Papa, o del partido conservador, o de la democracia cristiana, o como se llame? No, señor" (BCN, 39).

Incluso, además del Proyecto de Huneeus, hubo otras dos iniciativas similares. El diputado José Ramón Leiva, del Partido Democrático, presentó su proyecto el 19 de agosto de 1904, dos semanas después de Huneeus. Cuatro meses después, el 19 de enero de 1905, los diputados Radicales Ramón Corbalán y Ramón Carvallo presentaron otra moción argumentando que "incontestables razones de higiene, de moral y de orden social aconsejan e imponen al hombre el descanso después de seis días consecutivos de trabajo" (BCN, 10).

\section{Conclusiones}

Ciertamente, la Iglesia no fue la única responsable de los cambios en la percepción del rol del Estado, ya que el debate estaba presente en la sociedad toda y fue, incluso, ganando importancia a medida que la Cuestión Social iba también ocupando la mayoría de la discusión política en las tres primeras décadas del siglo XX; discusión que desembocó en el establecimiento de un embrionario Estado de bienestar. La opinión de la Iglesia sobre las atribuciones

14 Sólo en 1925, La Revista Católica se refirió nuevamente al descanso dominical al apoyar la petición del Intendente de Santiago para reformar la ley de 1907 (La Revista Católica, 1925: 476-477) 
del Estado en la resolución de los problemas sociales también se insertaba en los debates de la sociedad chilena sobre los "alcances del Estado en materia de regulación de las relaciones sociales", en cuanto el aparato estatal podía intervenir en la libertad que en un plano ideal debía regir las relaciones entre obreros y patrones o intervenir en la libertad individual (Yáñez, 2003: 162).

Las crisis sociales fueron el detonante de las discusiones sobre la necesidad de la intervención social del Estado. Este fue un período de discusiones y ensayos, por tanto, no hay una definición tajante sobre el rol del Estado, eso vendría a suceder sólo con la Constitución de 1925. De hecho, las leyes sociales dictadas a principios del siglo -como las de habitación obrera y descanso dominical estudiadas en este artículo- más que una intervención estatal representan, por una parte, la respuesta a la crisis desatada por la Cuestión social y el inicio, por otra, del proceso de transformación del rol del Estado en la sociedad. Es en este contexto donde debe enmarcase el aporte de la Iglesia a la discusión. Es una Iglesia que, por una parte, está respondiendo a los peligros de la laicización que puede representar la intervención estatal si ella sale de su marco de "gobierno de policía"; por otra parte, es una Iglesia que, al proponer una acción limitada del Estado, bajo el paraguas del catolicismo, confluye, inconscientemente, con el liberalismo político y económico cuyos excesos critica por dañar al obrero. Dentro de la Iglesia, un buen ejemplo es la pastoral del Arzobispo Juan Ignacio González de 1910. El prelado energéticamente promovió la Acción Social y al mismo tiempo llamaba por una más diligente acción del Estado en relación a los derechos sociales. Al no reconocer la predominancia del Estado para enfrentar los problemas sociales la Iglesia muestra que la institución aún se identificaba a sí misma como la institución que debía regular el orden social, no el Estado. En otras palabras, era una Iglesia aún en lucha contra la secularización.

\section{Referencias bibliográficas}

\section{Fuentes primarias}

a) Publicaciones periódicas

La Revista Católica, 1900-1929, Santiago.

\section{Fuentes secundarias}

a) Artículos y capítulos de libros

Bastías, M. (2015). "Intervención del Estado y derechos sociales. Transformaciones en el pensamiento jurídico chileno en la era de la Cuestión Social, 1880-1925", en Historia, $\mathrm{N}^{\circ} 48$, vol. 1, Santiago, pp. 11-42. 
Biblioteca del Congreso Nacional, Historia de la Ley No 1.990 Sobre descanso de un día en la semana. www.ben.cl, revisado el 25-I-2016.

Calvo, O. (2011). "Conocimiento desinteresado y ciencia americana. El Congreso Científico (1895-1916)", en Historia Crítica, № 45, Bogotá, pp. 86-113.

Casanova, M. (1905). "Pastoral acerca de las necesidades de mejorar la condición social del pueblo", en La Revista Católica, № 101, Santiago, pp. 421-430.

Casanova, M. (1891). "Pastoral que el Illmo. y Rvmo. Señor Doctor Mariano Casanova, Arzobispo de Santiago de Chile, dirige al clero y fieles al publicar la Encíclica de Nuestro Santísimo Padre Léon XIII sobre la condición de los obreros", en Grez, S. (Editor). (1995). La "Cuestión Social" en Chile: Ideas y Debates Precursores, 1804-1902. Santiago: Dirección de Bibliotecas, Archivos y Museos, Centro de Investigaciones Diego Barros Arana, pp. 379-387.

Casanova, M. (1889). "Pastoral sobre la intemperancia de la bebida", en Casanova, M. (1901). Obras pastorales del Ilmo. y Rmo. Señor Dr. Don Mariano Casanova, Arzobispo de Santiago de Chile. Friburgo: B. Herder, Librero-Editor Pontificio, pp.138-159.

Casanova, M. (1892). "Pastoral sobre la santificación del domingo", en Casanova, M. (1901). Obras pastorales del Ilmo. y Rmo. Señor Dr. Don Mariano Casanova, Arzobispo de Santiago de Chile. Friburgo: B. Herder, Librero-Editor Pontificio, pp. 225-253.

Cruzat, X. y Tironi, A. (1987). "El Pensamiento frente a la Cuestión Social en Chile", en Berríos, M. (Editor). Pensamiento en Chile, 1830-1910. Santiago: Nuestra América Ediciones, pp. 127-151.

Edwards, R. (1911). "Necesidad de Institutos de Reforma Social como medida de preparar la legislación social obrera", en Trabajos de la VII sección Ciencias Económicas y Sociales del Cuarto Congreso Científico ( $1^{\circ}$ Panamericano) celebrado en Santiago de Chile del 25 de diciembre de 1908 al 5 de enero de 1909 vol. 1. Santiago: Imprenta, Litografía y Encuadernación "Barcelona", pp. 143-145.

Góngora, M. (1985). "Libertad Política y Concepto Económico de Gobierno en Chile hacia 1915-1935", en Historia, № 20, Santiago, pp. 11-46.

González, J.I. (1910). "Pastoral sobre la Cuestión Social", en La Revista Católica, № 2111, Santiago, pp. 550-560.

Hidalgo, R. (2000). "La política de casas baratas a principios del siglo XX. El caso chileno" en Scripta Nova. Revista Electrónica de Geografía y Ciencias Sociales N ${ }^{\circ}$ 5. http://www.ub.edu.geocrit/sn 55.htm, revisado el 28-XII-2015.

Hidalgo, R. (2002). "Vivienda social y espacio urbano en Santiago de Chile. Una mirada retrospectiva a la acción del Estado en las primeras décadas del siglo XX", en Eure, № 83, Santiago, pp. 83-106. 
Hidalgo, R.; Errázuriz, T.; y Booth, R. (2005). "Las viviendas de la beneficencia católica en Santiago. Instituciones constructoras y efectos urbanos (1890-1920)", Historia, № 38. http://revistahistoria.uc.cl/estudios/1332/\#fnref-1332-36, revisado el 17-VII-2015.

León XIII (1891). Carta Encíclica Rerum Novarum del Sumo Pontífice León XIII sobre la situación de los obreros, revisado el 28-VII-2012.

Vergara, F. (2011). "La Encíclica Rerum Novarum y su recepción en Chile", en Moreno, R. (ed.) \& León, M. (coord.). Historia de la Iglesia en Chile. Tomo III. Los nuevos caminos: La Iglesia y el Estado. Santiago: Editorial Universitaria, pp. 353-365.

\section{b) Libros}

Andes, S. (2014). The Vatican and Catholic activism in Mexico and Chile. The politics of Transnational Catholicism, 1920-1940. Oxford: Oxford University Press.

Collier, S. \& Sater, W. (1996). A History of Chile, 1808-1994. Cambridge: Cambridge University Press.

De Ramón, A. (1992). Santiago de Chile (1541-1991) Historia de una Sociedad Urbana. Madrid: Editorial Mapfre.

Droguet, C. (2010). Historia del Instituto de Salud Pública de Chile, 1892-2009: Camino del bicentenario. Santiago: Instituto de Salud Pública.

Gobierno de Chile (1925). Constitución Política de la República de Chile. Santiago: Imprenta Universitaria.

Grez, S. (2010). Chile 1830/1880. Población y sociedad. Santiago: Taurus, Fundación Mapfre.

Primer Congreso Eucarístico de Santiago de Chile (1905). Santiago: Imprenta y Encuadernación Chile.

Romero, L.A. (2007). ¿Qué hacer con los pobres? Elites y sectores populares en Santiago de Chile, 1840-1895. Santiago: Ariadna Ediciones.

Rücker, M. (1913). Problemas Sociales. Santiago: Imprenta y Encuadernación Chile.

Rücker, M. (1914). Conferencias Populares. Barcelona: Tipografía Católica.

Rücker, M. (1915a). Conferencias Populares. Segunda Serie. Barcelona: Tipografía Católica.

Rücker, M. (1915b). Conferencias Populares. Tercera Serie. Barcelona: Tipografía Católica. 
Rücker, M. (1917). Notas Universitarias correspondientes a 1915 y 1916. Santiago: Imprenta Chile.

Saranyana, J.I. (2002). Teología en América Latina: el siglo de las teologías latinoamericanistas (1899-2001). Madrid: Iberoamericana.

Toniolo, G. (1898). La verdadera democracia: noción de la democracia cristiana. Santiago: Impr. de Emilio Pérez.

Vial, G. (1981). Historia de Chile (1891-1973), vol. II, part I, "La sociedad chilena en el cambio de siglo (1891-1920)". Santiago: Editorial Santillana.

Walter, R. (2005). Politics and Urban Growth in Santiago, Chile, 1891-1941. Stanford: Stanford University Press.

Yáñez, J. C. (2003). Estado, consenso y crisis social. El espacio público en Chile, 1900-1920. Santiago: Centro de Investigaciones Diego Barros Arana.

Yáñez, J.C (2008). La Intervención social en Chile y el nacimiento de la sociedad salarial, 1907-1932. Santiago: RIL. 